\title{
Lipid regulation of BK channel function
}

\section{Alex M. Dopico* and Anna N. Bukiya}

Department of Pharmacology, The University of Tennessee Health Science Center, Memphis, TN, USA

\section{Edited by:}

Thomas M. Weiger, University of Salzburg, Austria

\section{Reviewed by:}

Irena Levitan, University of Illinois at Chicago, USA

Rebecca Lam, Max Planck Institute of Biophysics, Germany

*Correspondence:

Alex M. Dopico, Department of Pharmacology, The University of Tennessee Health Science Center, 874 Union Ave., \#115, Memphis, TN 38163, USA

e-mail: adopico@uthsc.edu
This mini-review focuses on lipid modulation of $\mathrm{BK}$ (MaxiK, $\mathrm{BK}_{\mathrm{Ca}}$ ) current by a direct interaction between lipid and the BK subunits and/or their immediate lipid environment. Direct lipid-BK protein interactions have been proposed for fatty and epoxyeicosatrienoic acids, phosphoinositides and cholesterol, evidence for such action being less clear for other lipids. BK $\alpha$ (slo1) subunits are sufficient to support current perturbation by fatty and epoxyeicosatrienoic acids, glycerophospholipids and cholesterol, while distinct BK $\beta$ subunits seem necessary for current modulation by most steroids. Subunit domains or amino acids that participate in lipid action have been identified in a few cases: hslo1 Y318, cerebral artery smooth muscle (cbv1) R334,K335,K336, cbv1 seven cytosolic CRAC domains, slo1 STREX and $\beta 1$ T169,L172,L173 for docosahexaenoic acid, PIP 2, cholesterol, sulfatides, and cholane steroids, respectively. Whether these protein motifs directly bind lipids or rather transmit the energy of lipid binding to other areas and trigger protein conformation change remains unresolved. The impact of direct lipid-BK interaction on physiology is briefly discussed.

\section{Keywords: MaxiK channel, protein receptor site, protein-lipid interaction, lipids, electrophysiology}

Large conductance, $\mathrm{Ca}^{2+} /$ voltage-gated $\mathrm{K}^{+}(\mathrm{BK}$, maxiK, slo1) channels result from tetrameric association of $\alpha$ (slo1) subunits (Figure 1). In most tissues, slo1 channels are associated with small accessory proteins termed $\beta$ subunits. Four types of $\beta$ subunits have been identified, their expression being tissue-specific (Orio et al., 2002). This mini-review focuses on lipid modulation of BK current observed in cell-free systems and thus, studies supporting direct interactions between lipid and BK proteins and/or their immediate proteo-lipid environment.

\section{FATTY ACIDS}

Increase in BK channel activity by low $\mu \mathrm{M}$ FA has been reported in VSM (Kirber et al., 1992; Ahn et al., 1994; Dopico et al., 1994; Clarke et al., 2002, 2003; Martín et al., 2013) and GH3 cells (Denson et al., 2000), and following channel expression in HEK293 cells (Hoshi et al., 2013a-c) and Xenopus oocytes (Sun et al., 2007). FA-induced BK activation occurs at a wide range of $\left[\mathrm{Ca}^{2+}\right]_{\mathrm{i}}$, and $\left[\mathrm{Mg}^{2+}\right]_{\mathrm{i}}$ (Ahn et al., 1994), and in virtual absence of $\mathrm{Ca}_{\mathrm{i}}^{2+}$ (Clarke et al., 2002; Hoshi et al., 2013b). Moreover, FAs neither require voltage-sensor activation (Hoshi et al., 2013b) nor alter the slope of the activity-voltage relationship (Denson et al.,

Abbreviations: AA, arachidonic acid; BK, calcium- and voltage-gated, large conductance potassium; cAMP, cyclic adenosine monophosphate; $\mathrm{Ca}_{i}^{2+}$, intracellular calcium; CB, cannabinoid; $\mathrm{CHO}$, Chinese hamster ovary cells; CLR, cholesterol; CRAC, cholesterol recognition amino acid consensus; CTD, cytosolic tail domain; DHA, docosahexaenoic acid; DHET, 11,12-dihydroxyeicosatrienoic acid; EET, epoxyeicosatrienoic acid; EETe, epoxyeicosatetraenoic acid; FA, fatty acid; HEK, human embryonic kidney; GH3, rat pituitary tumor epithelial-like cells; HCN-1A, human cortical neuronal cells; HENA, 3-hydroxyolean-12-en30-oate; I/O, inside-out patch; LPI, lysophosphatidylinositol; LT, leukotriene; PC, phosphatidylcholine; PG, prostaglandins; PI, phosphoinositide; $\mathrm{PIP}_{2}$, phosphatidylinositol 4,5-bisphosphate; PK, protein kinase; Po, open probability; RCK, regulator of conductance for potassium; SM, smooth muscle; SPL, sphingolipid; TM, transmembrane; TxA2, thromboxane A2; VSM, vascular smooth muscle.
2000). In particular, DHA favors channel dwelling in conducting states by destabilizing the closed conformation of the pore (Hoshi et al., 2013a,b).

FA-induced BK activation does not correlate with changes in membrane fluidity or production of free radicals and oxygen metabolites (Denson et al., 2000). In addition, FA action persists in cell-free, membrane patches (Denson et al., 2000; Clarke et al., 2002; Hoshi et al., 2013b). The membrane-impermeable arachidonoyl-CoA potentiates current only when applied to the cytosolic side of the membrane patch (Denson et al., 2000; Sun et al., 2008), suggesting that the FA-recognition site(s) is accessible from the inner membrane leaflet.

Presence of a negatively charged head-group seems critical for FA “direct" action on BK channels. This action, however, persists after screening membrane surface charge with high-ionic strength solution (Clarke et al., 2002). Structure-activity studies reveal that unsaturated FAs (DHA, arachidonic, and oleic acids) enhance steady-state amplitude and slow inactivation of hslo $1+\beta 2$ currents whereas saturated FAs fail to do so (Sun et al., 2007). Cis-unsaturated FAs increase GH3 cell BK current whereas saturated or trans-unsaturated FAs have no effect (Denson et al., 2000). On the other hand, long-chain FAs are more effective than short-chain counterparts in activating VSM BK channels (Ahn et al., 1994; Clarke et al., 2002). The mechanisms and targets underlying differential modulation of BK currents by FA of variant structure remain unidentified.

Channel subunit composition plays a critical role in the final effect of FA on BK current. In the same expression system, DHA potentiates and fails to alter hslol-mediated and dslo1-mediated current, respectively (Hoshi et al., 2013c). These findings are consistent with the existence of specific, DHArecognizing sites in slo1 proteins, with hslo1 Y318 playing a 


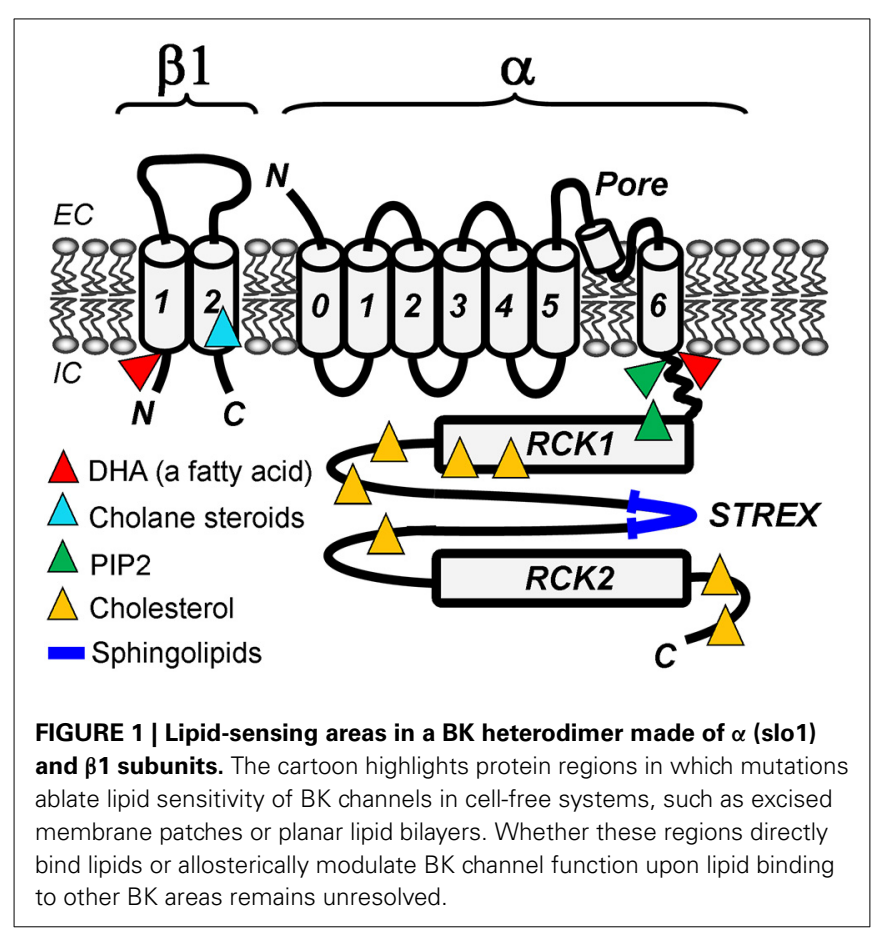

critical role in DHA-sensing (Hoshi et al., 2013c). In addition, DHA potentiation of hslol current is amplified by BK $\beta 1$ and $\beta 4$ subunits (Hoshi et al., 2013a). On the other hand, AA slows inactivation and potentiates current mediated by $\beta 2$ - or $\beta 3$ containing BK channels. In contrast, long-chain acyl-CoAs facilitate hslo $2+\beta 2$ inactivation and thus, inhibit overall current (Sun et al., 2008). The presence of opposite charge on residues at positions 11 (N-terminus) and 18 in BK $\beta$ transmembrane domain- 1 (TM1) is crucial for DHA action in presence of $\beta 1$ and $\beta 4$ (Hoshi et al., 2013a). It remains unclear whether these residues represent an FA binding site or transduce FA-docking energy into gating modification. Consistent with modulatory or "allosteric" mechanisms, AA inactivates $\alpha+\beta 2$-mediated currents but fails to affect inactivation of current by the $\beta 2$-inactivating ball peptide alone, suggesting that AA does not interact with the ball peptide itself (Sun et al., 2007).

The physiological and pathophysiological consequences of BK channel modulation by FAs are under investigation. AA eliminates a transient $\mathrm{K}^{+}$current in neocortical neurons (Sun et al., 2007), which should drastically alter excitability. BK currents mediate AA-induced relaxation of pulmonary artery, yet the exact contribution of a direct FA-BK interaction to this AA action remains unclear (Guerard et al., 2004). However, omega-3 FAs lower blood pressure by directly activating BK channels in VSM (Hoshi et al., 2013b).

\section{PROSTANOIDS}

$\mathrm{PGI}_{2}, \mathrm{PGE}_{2}$, unoprostone and AH13205 activate BK currents in retinal pericytes (Burnette and White, 2006), coronary artery SM (Zhu et al., 2002), HCN-1A (Cuppoletti et al., 2007) and trabecular meshwork cells (Stumpff et al., 2005), respectively. In contrast, U46619 inhibits BK current when the channel is coexpressed with thromboxane $\mathrm{A}_{2}\left(\mathrm{TxA}_{2}\right)$ receptors in HEK293 cells
(Li et al., 2013). $\mathrm{PGI}_{2}$ - and $\mathrm{PGE}_{2}$-induced $\mathrm{BK}$ activation require cAMP-stimulated cross-activation of PKG, but not PKA (Hata et al., 2000; Zhu et al., 2002). In VSM, however, $\mathrm{PGI}_{2}$ activation of BK current involves a cAMP-independent, Gs protein-dependent component (Tanaka et al., 2004). In turn, U46619 inhibits channel activity in cell-free patches, an action that involves independent associations between channel-forming subunits, $\mathrm{BK} \beta 1$, and $\mathrm{TxA}_{2}$ receptors. A direct interaction between prostanoids and $\mathrm{BK}$ subunits, however, remains unclear.

Prostanoid-induced BK activation may contribute to the relaxant activity of $\mathrm{PGE}_{2}$ in trabecular meshworks (Wang et al., 1998; Stumpff et al., 2005), and $\mathrm{PGI}_{2}$-induced VSM relaxation (Tanaka et al., 2004) with consequent retinal vasodilation and blood flow augmentation (Hata et al., 2000). Prostanoid-BK interactions may provide a basis for using $\mathrm{PGI}_{2}$-mimetics against pulmonary hypertension (Benyahia et al., 2013). Such interactions may also underlie unoprostone-induced hyperpolarization and consequent protection of cortical neurons against glutamate-induced $\mathrm{Ca}_{\mathrm{i}}^{2+}$ dysregulation (Cuppoletti et al., 2007).

\section{EPOXYEICOSATRIENOIC ACIDS AND LEUKOTRIENES}

EET and derivatives activate BK channels in VSM (Wu et al., 2000; Zhang et al., 2001; Lauterbach et al., 2002; Archer et al., 2003; Dimitropoulou et al., 2007; Loot et al., 2012) and non-vascular SM (Benoit et al., 2001), cortical collecting duct (Sun et al., 2009), pituitary GH3 (Wu et al., 2000), HEK293 (Fukao et al., 2001), and adrenal chromaffin cells (Twitchell et al., 1997), and crude airway SM microsomes reconstituted into lipid bilayers (Benoit et al., 2001). EET-related epoxyeicosatetraenoic acids (EETe) and 5-oxo-eicosatetraenoic acid potentiate BK current in human pulmonary artery and distal bronchi (Morin et al., 2007, 2009), and cerebral and mesenteric VSM (Hercule et al., 2007). EET and EETe effective concentrations range from $\mathrm{nM}$ to low $\mu \mathrm{M}$ (Wu et al., 2000; Benoit et al., 2001; Lauterbach et al., 2002; Hercule et al., 2007; Morin et al., 2009).

EET increases BK current without affecting unitary conductance (Wu et al., 2000; Benoit et al., 2001; Fukao et al., 2001). Rather, EET and 11,12-dihydroxyeicosatrienoic acid (DHET) increase channel open probability (Po) by lengthening open and shortening closed times (Wu et al., 2000; Lu et al., 2001). Modification of gating by EET and EETe is observed across a wide voltage range (Wu et al., 2000; Lauterbach et al., 2002; Hercule et al., 2007) and unaffected by strong buffering of $\mathrm{Ca}_{i}^{2+}$ (Benoit et al., 2001; Hercule et al., 2007). However, DHET fails to activate BK channels in absence of $\mathrm{Ca}_{\mathrm{i}}^{2+}$ (Lu et al., 2001). EET-induced BK channel activation is suppressed by anti-Gas antibody (Fukao et al., 2001), and by protein phosphatase 2A inhibitor (Dimitropoulou et al., 2007). However, EET-induced BK activation could be observed in cellfree patches (Wu et al., 2000; Dimitropoulou et al., 2007) and following channel reconstitution into artificial lipid bilayers (Benoit et al., 2001). EET-induced activation of recombinant channels expressed in HEK293 cells does not require $\beta 1$ subunits (Fukao et al., 2001). Consistently, EETe action on BK channels is preserved in cerebral and mesenteric VSM lacking BK $\beta 1$ subunits (Hercule et al., 2007). Collectively, these findings point at the $\mathrm{BK} \beta 1$ subunit and its lipid 
microenvironment as the primary target of EETs and related compounds.

It is noteworthy that 11,12 -EET but neither 8,9 - nor 14,15 EET, activates BK channels in cortical collecting duct cells (Sun et al., 2009). However, 14,15-EET activates BK channels in insideout patches from GH3 cells (Wu et al., 2000). In addition, while equipotent in activating coronary artery SM BK channels, several DHETs show a reduced efficacy when compared to 11,12-EET (Lu et al., 2001). Structural specificity in EET action on BK channels is consistent with involvement of distinct EET-recognizing protein sites. In contrast, data from coronary microvessel SM cellfree membrane patches demonstrate a low structural specificity for EET action, as several EET regioisomers and enantiomers, epoxyeicosaquatraenoic, and epoxydocosatetraenoic acids activate $\mathrm{BK}$ channels with similar potencies and efficacies (Zhang et al., 2001).

In airway SM, 20-hydroxyeicosatetraenoic acid (20-HETE) and EETs cause membrane hyperpolarization and relaxation of human distal bronchi (Morin et al., 2007, 2009). Likewise, EETinduced BK activation leads to hyperpolarization and dilation of internal mammary (Archer et al., 2003), pulmonary (Morin et al., 2007) and mesenteric arteries (Dimitropoulou et al., 2007). However, EET-mediated SM dilation may be counteracted by EET-stimulated physical association of $\mathrm{BK} \alpha$ and $\beta 1$ subunits in mitochondria: this association enhances mitochondria BK function, leading to loss of mitochondrial membrane potential and thus, depolarization, as reported in pulmonary VSM (Loot et al., 2012). Consistently, EETs fail to hyperpolarize the membrane and relax isolated internal carotid artery (Chataigneau et al., 1998). Finally, BK activation by EET plays an important role in flowstimulated $\mathrm{K}^{+}$secretion in the cortical collecting duct (Sun et al., 2009), and possibly in regulating adreno-chromaffin cell secretion (Twitchell et al., 1997).

LTA4, LTB4, LTC4, LTD4, and LTE4 $(\mathrm{nM}-\mu \mathrm{M})$ have been tested on $\beta 1$ subunit-containing recombinant $\mathrm{BK}$ channels in Xenopus oocyte I/O patches, with only LTB4 significantly increasing channel activity (Bukiya and Dopico, 2013a). This finding raises the hypothesis that $\mathrm{BK}$ activation via LTB4-BK interaction reduces LT receptor-mediated, SM contraction by LTB4 (Rosenblum, 1985; Lawson et al., 1986; Peters-Golden and Henderson, 2007).

\section{CANNABINOIDS}

BK channel activation by cannabinoids was detected in myometrial strips (Houlihan et al., 2010), trabecular meshwork cells (Stumpff et al., 2005), ophthalmic artery (Romano and Lograno, 2006), coronary (White et al., 2001) and aortic SM (Sade et al., 2006), and HEK293 cells expressing BK $\alpha, \alpha+\beta 1$ or $\alpha+\beta 4$ subunits (Sade et al., 2006; Godlewski et al., 2009). In contrast, $\mu \mathrm{M}$ methanandamide decreases BK activity in mesenteric and aortic SM (Bol et al., 2012). Likewise, virodhamine and synthetic analogs inhibit slo1 channels expressed in HEK293 cells (Godlewski et al., 2009).

The differential effects of cannabinoids on BK activity raised speculation on involvement of several mechanisms and molecular entities in cannabinoid action on BK channels. However, cannabinoid activation of SM BK channels involves neither
CB1 or CB2 receptors (White et al., 2001; Romano and Lograno, 2006) nor cannabinoid metabolites (White et al., 2001). Moreover, studies in HEK293 cells rule out involvement of G-proteins and protein kinases (Sade et al., 2006), leading to the hypothesis that a direct cannabinoid-BK channel interaction mediates cannabinoid-induced channel activation (Godlewski et al., 2009). However, methanandamide fails to activate BK channels in cell-free medium (Sade et al., 2006; Godlewski et al., 2009), suggesting that cannabinoid action requires cellular signaling. This signal(s) would likely interact on the slo1 protein, as cannabinoid-induced BK activation is observed in homomeric slo1 (Sade et al., 2006; Godlewski et al., 2009). Interestingly, cannabinoid-induced potentiation of slo1 current is lost after membrane CLR depletion and restored upon CLR repletion (Godlewski et al., 2009), with the slo1 CTD providing several CLR-recognition domains that mediate CLR modulation of slo1 activity (Singh et al., 2012) (see below).

Cannabinoid-induced BK activation seems to play a role in endothelium-dependent vasodilation (White et al., 2001; Romano and Lograno, 2006; Godlewski et al., 2009), modulation of ocular outflow (Stumpff et al., 2005), and myometrial quiescence (Houlihan et al., 2010). In addition, BK activation might contribute to cannabinoid-induced neuroprotection; in particular, to cannabidiol-induced protections against pentylenetetrazolinduced seizure (Shirazi-zand et al., 2013).

\section{GLYCEROPHOSPHOLIPIDS}

Glycerophospholipid actions on BK function have been extensively studied in artificial lipid bilayers. Glycerophospholipidinduced changes in unitary conductance (Crowley et al., 2005) and Po (Chang et al., 1995; Crowley et al., 2005; Yuan et al., 2007) have been reported. Increase in slol conductance is linked to net negative charge in the glycerophospholipid headgroup (Crowley et al., 2005). In turn, data from bilayers made of variant PCs show that Po decreases with increase in bilayer thickness from PC14:1 to PC 22:1 while increasing from PC22:1 to PC24:1 (Yuan et al., 2007). While this dual profile of Po change is paralleled by changes in mean closed times, BK mean open time increases monotonically with bilayer thickness (Yuan et al., 2007). Moreover, increased open times have been linked to an increase in the glycerophospholipid headgroup cross-sectional area (Chang et al., 1995).

The mechanisms underlying glycerophospholipid-induced modification of BK open and closed times and thus, Po, remain unknown. Putative mechanisms include modification in the physical properties of the lipid microenvironment of the slo1 protein (Chang et al., 1995; Crowley et al., 2005; Yuan et al., 2007); changes in lateral stress imposed by the increasing headgroup size (Chang et al., 1995), perturbation of surface charge density and distribution by negatively charged headgroups (Moczydlowski et al., 1985), and hydrophobic mismatch between protein and bilayer thickness (Yuan et al., 2007). Specific glycerophospholipid-slo1 protein binding cannot be ruled out (Crowley et al., 2005), and gains increasing acceptance as evidence documenting direct binding of membrane lipids to transmembrane proteins keeps growing (Yeagle, 2014). 


\section{PHOSPHOINOSITIDES}

PI-induced BK activation has been reported in cerebral artery and skeletal muscle myocytes (Vaithianathan et al., 2008), and with recombinant channels expressed in Xenopus oocytes (Vaithianathan et al., 2008; Tang et al., 2014). Phosphatidylinositol 4,5-bisphosphate $\left(\mathrm{PIP}_{2}\right)$-induced $\mathrm{BK}$ activation is independent of $\mathrm{PIP}_{2}$ metabolites, and occurs in absence of changes in unitary conductance or voltage-gating. However, this $\mathrm{PIP}_{2}$ action requires $\mathrm{Ca}_{\mathrm{i}}^{2+}$. Moreover, $\mathrm{PIP}_{2}$ facilitates $\mathrm{Ca}_{\mathrm{i}}^{2+}$-driven gating (Vaithianathan et al., 2008). Very recent work points at the KDRDD loop in the slo1 RCK1 domain as mediator of functional coupling between $\mathrm{PIP}_{2}$ - and $\mathrm{Ca}_{\mathrm{i}}^{2+}$-regulation of channel activity (Tang et al., 2014): in absence of $\mathrm{Ca}_{\mathrm{i}}^{2+}$, the slo1 RCK1 KDRDD loop decreases the channel's affinity for $\mathrm{PIP}_{2}$ whereas in presence of $\mathrm{Ca}_{\mathrm{i}}^{2+}$ the inhibitory modulation of such loop on $\mathrm{PIP}_{2}$ affinity is relieved by $\mathrm{Ca}^{2+}-\mathrm{D} 367$ coordination (Tang et al., 2014).

PI-induced BK activation increases with increase in negative charge within the PI headgroup. On the other hand, the more water-soluble analogues $\mathrm{diC} 4$ and $\operatorname{diC} 8$ are $\sim 10$-fold less effective than $\mathrm{PIP}_{2}$ in increasing $\mathrm{BK}$ activity, a difference that can be explained by their lower affinity to a site(s) and/or by their poor partitioning in the lipid membrane. If membrane partitioning is required for PI to access its site of action, this site should be located in the TM or the intracellular region of the protein, as lipids were more effective when applied to the intracellular side of the membrane. Indeed, the triplet R334,K335,K336 located after S6 in the BK channel-forming cbv1 subunit CTD has been identified as the PI-sensor (Vaithianathan et al., 2008). PIP $2^{-}$ induced BK activation is observed in homomeric cbv1 channels and drastically amplified by $\beta 1$ subunits. Whether this amplification involves $\mathrm{PIP}_{2}$-recognition sites in $\beta 1$ or distinct coupling between $\beta 1$ and $\mathrm{PIP}_{2}$-bound cbv1 is under investigation.

Manipulation of endogenous $\mathrm{PIP}_{2}$ levels leads to endotheliumindependent, BK-mediated cerebral artery dilation, which suggests that VSM $\mathrm{PIP}_{2}$ regulates myogenic tone via $\mathrm{BK}$ activation (Vaithianathan et al., 2008).

\section{LYSOPHOSPHOLIPIDS}

In $\mathrm{I} / \mathrm{O}$ patches from an umbilical vein-derived, endothelial cell line, LPI increases BK Po at sub- $\mu \mathrm{M} \mathrm{Ca}_{\mathrm{i}}^{2+}$ and following low basal (pre-LPI) activity while decreasing Po at $\mu \mathrm{M} \mathrm{Ca}_{\mathrm{i}}^{2+}$ and following high basal activity. LPI has no effect in the absence of $\mathrm{Ca}_{\mathrm{i}}^{2+}$ (Bondarenko et al., 2011). The structural bases of LPI$\mathrm{BK}$ interaction and its dependence on $\mathrm{Ca}_{\mathrm{i}}^{2+}$ remain unknown. The gating modifications, however, seem complex, as LPI effect results from changes in both open and closed time distributions. Modulation of BK current by endogenous LPI could play a role in the potentiation of endothelial cell hyperpolarization by low histamine concentrations (Bondarenko et al., 2011).

\section{SPHINGOLIPIDS (SPLs)}

Sub- $\mu \mathrm{M}$ to low $\mu \mathrm{M}$ SPLs and their metabolites modulate BK activity in pinealocytes (Chik et al., 2001), CHO cells (Chi and Qi, 2006) and an endothelial cell line (Kim et al., 2006). Sulphatides, cerebroside termitomycesphin-A and sphingosine-1-phosphate increase BK current (Chik et al., 2001; Chi and Qi, 2006; Kim et al., 2006; Xu et al., 2011) while ceramides reduce current via a PKC-dependent pathway (Chik et al., 2001).

SPL-induced BK current potentiation is dose-dependent, reversible (Kim et al., 2006), and occurs in absence of unitary conductance modification (Xu et al., 2011). SPL action is independent of $\mathrm{Ca}_{\mathrm{i}}^{2+}$ and $\mathrm{G}$ protein-coupled receptors (Chi and Qi, 2006; Kim et al., 2006; Xu et al., 2011). Moreover, deletion of the STREX insert in the slo1 CTD reduces channel activation by sulphatides (Chi and Qi, 2006) and totally suppresses the channel's sensitivity to termitomycesphin-A (Xu et al., 2011).

SPL modulation of BK activity could play a role in $\mathrm{Ca}^{2+}$ mobilization in endothelial cells (Kim et al., 2006), circadian regulation (Chik et al., 2001), and neuroprotection (Chi and Qi, 2006; Xu et al., 2011).

\section{CHOLESTEROL, OTHER STEROIDS, AND VITAMIN D}

A comprehensive and recent review on modulation of $\mathrm{BK}$ channels by CLR and related cholestanes is provided elsewhere (Dopico et al., 2012a,b). In brief, excessive membrane CLR usually decreases BK current, which has been attributed to direct and indirect mechanisms. For decades, CLR action on BK activity has been primarily linked to modification in membrane physical properties by CLR insertion (Chang et al., 1995; Crowley et al., 2003; Lundbaek, 2008). Direct CLR-BK interactions via seven CLR-recognition amino acid consensus (CRAC) motifs in the slo1 CTD were proposed (Singh et al., 2012).

In most cases, bile acids and related cholanes, pregnanes, androstanes, and estranes increase BK current, with eventual modification of physiology (reviewed in Dopico et al., 2012a). Later work identified a cholane-recognition site in the BK $\beta 1$ TM2 where cholane docks via hydrogen bonding between its hydroxyl and T169, as well as via van der Waals interactions between the steroidal rings and L172,L173 (Bukiya et al., 2011). This site accommodates non-steroidal compounds, such as sodium 3-hydroxyolean-12-en-30-oate (HENA). Cholane and HENA recognition results in endothelium-independent, cerebral artery dilation via BK activation (Bukiya et al., 2013b). Because the identified site is found in the SM-abundant $\beta 1$ and not in other BK $\beta$ s (2-4), such a site represents an attractive target for rationale design of agents to counteract SM enhanced contraction, as found in asthma, cerebral vasospasm, systemic hypertension, erectile, bladder and uterine dysfunction (Patil et al., 2008; Bukiya et al., 2012).

Considering: 1-the critical roles of both vitamin D and BK channel function in maintaining healthy blood pressure levels (Holtzclaw et al., 2011; Basit, 2013), and 2-the structural similarity of vitamin D with the cholane lithocholic acid, which activates BK channels (see above), it was hypothesized that vitamin D increased BK activity. Indeed, $\mu \mathrm{M}$ vitamin D3 and $25-\mathrm{OH}$ vitamin D3 increase $\beta 1$-containing, BK-mediated currents after expression in Xenopus oocytes (Bukiya et al., unpublished). The consequences of vitamin $\mathrm{D}$ action on $\mathrm{BK}$ currents are under investigation.

\section{CONCLUSIONS}

Modulation of BK current by direct (e.g., independent of cell integrity, signaling or lipid metabolism) interaction between lipid 
ligand and BK subunits has been reported for a wide variety of lipid species. For some lipids (e.g., cholesterol), lipid-BK channelforming (slo1) subunit interaction accounts for most of the lipid effect. The majority of lipid-sensing regions in slol have been mapped to its intracellular tail domain. Whether these regions directly bind lipids or modulate BK channel function following lipid binding to other slo1 areas remains to be determined. For other lipids (e.g., cholanes), accessory $\beta$ subunits are necessary for lipid action. Still for others (e.g., $\mathrm{PIP}_{2}$ ), slo1 subunits suffice for lipid action, yet $\beta$ subunits drastically modify the lipid's final effect. In most cases, the impact of direct BK channel-lipid interaction on organ function is under investigation.

\section{ACKNOWLEDGMENT}

\section{Supported by HL104631 and AA11560 (Alex M. Dopico).}

\section{REFERENCES}

Ahn, D. S., Kim, Y. B., Lee, Y. H., Kang, B. S., and Kang, D. H. (1994). Fatty acids directly increase the activity of $\mathrm{Ca}^{(2+)}$-activated $\mathrm{K}^{+}$channels in rabbit coronary smooth muscle cells. Yonsei Med. J. 35, 10-24.

Archer, S. L., Gragasin, F. S., Wu, X., Wang, S., McMurtry, S., Kim, D. H., et al. (2003). Endothelium-derived hyperpolarizing factor in human internal mammary artery is 11,12-epoxyeicosatrienoic acid and causes relaxation by activating smooth muscle $\mathrm{BK}_{(\mathrm{Ca})}$ channels. Circulation 107, 769-776. doi: 10.1161/01.CIR.0000047278.28407.C2

Basit, S. (2013). Vitamin D in health and disease: a literature review. Br. J. Biomed. Sci. 70, 161-172.

Benoit, C., Renaudon, B., Salvail, D., and Rousseau, E. (2001). EETs relax airway smooth muscle via an EpDHF effect: $\mathrm{BK}_{(\mathrm{Ca})}$ channel activation and hyperpolarization. Am. J. Physiol. Lung Cell. Mol. Physiol. 280, L965-L973.

Benyahia, C., Boukais, K., Gomez, I., Silverstein, A., Clapp, L., Fabre, A., et al. (2013). A comparative study of PGI2 mimetics used clinically on the vasorelaxation of human pulmonary arteries and veins, role of the DP-receptor. Prostaglandins Other Lipid Mediat. 107, 48-55. doi: 10.1016/j.prostaglandins.2013.07.001

Bol, M., Leybaert, L., and Vanheel, B. (2012). Influence of methanandamide and CGRP on potassium currents in smooth muscle cells of small mesenteric arteries. Pflugers Arch. 463, 669-677. doi: 10.1007/s00424-012-1083-1

Bondarenko, A. I., Malli, R., and Graier, W. F. (2011). The GPR55 agonist lysophosphatidylinositol acts as an intracellular messenger and bidirectionally modulates $\mathrm{Ca}^{2+}$-activated large-conductance $\mathrm{K}^{+}$channels in endothelial cells. Pflugers Arch. 461, 177-189. doi: 10.1007/s00424-010-0898-x

Bukiya, A., and Dopico, A. (2013a). "Leukotriene B4 activation of arterial smooth muscle BK channels," in Biophysical Society 57th Annual Meeting. (Philadelphia, PA).

Bukiya, A. N., McMillan, J. E., Fedinec, A. L., Patil, S. A., Miller, D. D., Leffler, C. W., et al. (2013b). Cerebrovascular dilation via selective targeting of the cholane steroid-recognition site in the BK channel $\beta 1$-subunit by a novel nonsteroidal agent. Mol. Pharmacol. 83, 1030-1044. doi: 10.1124/mol.112. 083519

Bukiya, A. N., Patil, S. A., Li, W., Miller, D. D., and Dopico, A. M. (2012). Calciumand voltage-gated potassium (BK) channel activators in the $5 \beta$-cholanic acid$3 \alpha$-ol analogue series with modifications in the lateral chain. Chem. Med.Chem. 7, 1784-1792. doi: 10.1002/cmdc.201200290

Bukiya, A. N., Singh, A. K., Parrill, A. L., and Dopico, A. M. (2011). The steroid interaction site in transmembrane domain 2 of the large conductance, voltage- and calcium-gated potassium (BK) channel accessory $\beta 1$ subunit. Proc. Natl. Acad. Sci. U.S.A. 108, 20207-20212. doi: 10.1073/pnas.1112 901108

Burnette, J. O., and White, R. E. (2006). PGI2 opens potassium channels in retinal pericytes by cyclic AMP-stimulated, cross-activation of PKG. Exp. Eye Res. 83, 1359-1365. doi: 10.1016/j.exer.2006.07.011

Chang, H. M., Reitstetter, R., and Gruener, R. (1995). Lipid-ion channel interactions: increasing phospholipid headgroup size but not ordering acyl chains alters reconstituted channel behavior. J. Membr. Biol. 145, 13-19. doi: 10.1007/BF00233303
Chataigneau, T., Félétou, M., Duhault, J., and Vanhoutte, P. M. (1998). Epoxyeicosatrienoic acids, potassium channel blockers and endotheliumdependent hyperpolarization in the guinea-pig carotid artery. Br. J. Pharmacol. 123, 574-580. doi: 10.1038/sj.bjp.0701629

Chi, S., and Qi, Z. (2006). Regulatory effect of sulphatides on $\mathrm{BK}_{\mathrm{Ca}}$ channels. Br. J. Pharmacol. 149, 1031-1038. doi: 10.1038/sj.bjp.0706947

Chik, C. L., Li, B., Karpinski, E., and Ho, A. K. (2001). Ceramide inhibits the outward potassium current in rat pinealocytes. J. Neurochem. 79, 339-348. doi: 10.1046/j.1471-4159.2001.00566.x

Clarke, A. L., Petrou, S., Walsh, J. V. Jr., and Singer, J. J. (2002). Modulation of $\mathrm{BK}_{(\mathrm{Ca})}$ channel activity by fatty acids: structural requirements and mechanism of action. Am. J. Physiol. Cell. Physiol. 283, C1441-C1453. doi: 10.1152/ajpcell.00035.2002

Clarke, A. L., Petrou, S., Walsh, J. V. Jr., and Singer, J. J. (2003). Site of action of fatty acids and other charged lipids on BKCa channels from arterial smooth muscle cells. Am. J. Physiol. Cell. Physiol. 284, C607-619. doi: 10.1152/ajpcell.00364.2002

Crowley, J. J., Treistman, S. N., and Dopico, A. M. (2003). Cholesterol antagonizes ethanol potentiation of human brain $\mathrm{BK}_{\mathrm{Ca}}$ channels reconstituted into phospholipid bilayers. Mol. Pharmacol. 64, 365-372. doi: 10.1124/mol. 64.2.365

Crowley, J. J., Treistman, S. N., and Dopico, A. M. (2005). Distinct structural features of phospholipids differentially determine ethanol sensitivity and basal function of BK channels. Mol. Pharmacol. 68, 4-10.

Cuppoletti, J., Malinowska, D. H., Tewari, K. P., Chakrabarti, J., and Ueno, R. (2007). Cellular and molecular effects of unoprostone as a BK channel activator. Biochim. Biophys. Acta. 1768, 1083-1092. doi: 10.1016/j.bbamem.2006. 12.015

Denson, D. D., Wang, X., Worrell, R. T., and Eaton, D. C. (2000). Effects of fatty acids on BK channels in $\mathrm{GH}(3)$ cells. Am. J. Physiol. Cell. Physiol. 279, C1211-C1219.

Dimitropoulou, C., West, L., Field, M. B., White, R. E., Reddy, L. M., Falck, J. R., et al. (2007). Protein phosphatase $2 \mathrm{~A}$ and $\mathrm{Ca}^{2+}$-activated $\mathrm{K}^{+}$channels contribute to 11,12-epoxyeicosatrienoic acid analog mediated mesenteric arterial relaxation. Prostaglandins Other Lipid Mediat. 83, 50-61. doi: 10.1016/j.prostaglandins.2006.09.008

Dopico, A., Bukiya, A., and Singh, A. (2012a). "Differential contribution of BK subunits to nongenomic regulation of channel function by steroids," in Cholesterol Regulation of Ion Channels and Receptors, eds I. Levitan and F. Barrantes (Hoboken, NJ: J. Wiley and sons), 109-134. doi: 10.1002/978111834 2312.ch6

Dopico, A. M., Bukiya, A. N., and Singh, A. K. (2012b). Large conductance, calcium- and voltage-gated potassium (BK) channels: regulation by cholesterol. Pharmacol. Ther. 135, 133-150. doi: 10.1016/j.pharmthera.2012.05.002

Dopico, A. M., Kirber, M. T., Singer, J. J., and Walsh, J. V. Jr. (1994). Membrane stretch directly activates large conductance $\mathrm{Ca}^{(2+)}$-activated $\mathrm{K}^{+}$channels in mesenteric artery smooth muscle cells. Am. J. Hypertens. 7, 82-89.

Fukao, M., Mason, H. S., Kenyon, J. L., Horowitz, B., and Keef, K. D. (2001). Regulation of $\mathrm{BK}_{(\mathrm{Ca})}$ channels expressed in human embryonic kidney 293 cells by epoxyeicosatrienoic acid. Mol. Pharmacol. 59, 16-23.

Godlewski, G., Offertáler, L., Osei-Hyiaman, D., Mo, F. M., Harvey-White, J., Liu, J., et al. (2009). The endogenous brain constituent $\mathrm{N}$-arachidonoyl L-serine is an activator of large conductance $\mathrm{Ca}^{2+}$-activated $\mathrm{K}^{+}$channels. J. Pharmacol. Exp. Ther. 328, 351-361. doi: 10.1124/jpet.108.144717

Guerard, P., Goirand, F., Fichet, N., Bernard, A., Rochette, L., Morcillo, E. J., et al. (2004). Arachidonic acid relaxes human pulmonary arteries through K+ channels and nitric oxide pathways. Eur. J. Pharmacol. 501, 127-135. doi: 10.1016/j.ejphar.2004.08.007

Hata, Y., Clermont, A., Yamauchi, T., Pierce, E. A., Suzuma, I., Kagokawa, H., et al. (2000). Retinal expression, regulation, and functional bioactivity of prostacyclin-stimulating factor. J. Clin. Invest. 106, 541-550. doi: 10.1172/JCI8338

Hercule, H. C., Salanova, B., Essin, K., Honeck, H., Falck, J. R., Sausbier, M., et al. (2007). The vasodilator 17,18-epoxyeicosatetraenoic acid targets the poreforming BK alpha channel subunit in rodents. Exp. Physiol. 92, 1067-1076. doi: 10.1113/expphysiol.2007.038166

Holtzclaw, J. D., Grimm, P. R., and Sansom, S. C. (2011). Role of BK channels in hypertension and potassium secretion. Curr. Opin. Nephrol. Hypertens. 20, 512-517. doi: 10.1097/MNH.0b013e3283488889 
Hoshi, T., Tian, Y., Xu, R., Heinemann, S. H., and Hou, S. (2013a). Mechanism of the modulation of BK potassium channel complexes with different auxiliary subunit compositions by the omega-3 fatty acid DHA. Proc. Natl. Acad. Sci. U.S.A. 110, 4822-4827. doi: 10.1073/pnas.1222 003110

Hoshi, T., Wissuwa, B., Tian, Y., Tajima, N., Xu, R., Bauer, M., et al. (2013b). Omega-3 fatty acids lower blood pressure by directly activating largeconductance $\mathrm{Ca}^{2+}$-dependent $\mathrm{K}^{+}$channels. Proc. Natl. Acad. Sci. U S A. 110, 4816-4821. doi: 10.1073/pnas.1221997110

Hoshi, T., Xu, R., Hou, S., Heinemann, S. H., and Tian, Y. (2013c). A point mutation in the human Slol channel that impairs its sensitivity to omega-3 docosahexaenoic acid. J. Gen. Physiol. 142, 507-522. doi: 10.1085/jgp.201311061

Houlihan, D. D., Dennedy, M. C., and Morrison, J. J. (2010). Effects of abnormal cannabidiol on oxytocin-induced myometrial contractility. Reproduction 139, 783-788. doi: 10.1530/REP-09-0496

Kim, M. Y., Liang, G. H., Kim, J. A., Kim, Y. J., Oh, S., and Suh, S. H. (2006). Sphingosine-1-phosphate activates $\mathrm{BK}_{\mathrm{Ca}}$ channels independently of $\mathrm{G}$ proteincoupled receptor in human endothelial cells. Am. J. Physiol. Cell. Physiol. 290, C1000-C1008. doi: 10.1152/ajpcell.00353.2005

Kirber, M. T., Ordway, R. W., Clapp, L. H., Walsh, J. V. Jr., and Singer, J. J. (1992). Both membrane stretch and fatty acids directly activate large conductance $\mathrm{Ca}^{(2+)}$-activated $\mathrm{K}^{+}$channels in vascular smooth muscle cells. FEBS Lett. 297, 24-28. doi: 10.1016/0014-5793(92)80319-C

Lauterbach, B., Barbosa-Sicard, E., Wang, M. H., Honeck, H., Kärgel, E., Theuer, J., et al. (2002). Cytochrome P450-dependent eicosapentaenoic acid metabolites are novel BK channel activators. Hypertension 39, 609-613. doi: 10.1161/hy0202.103293

Lawson, C., Bunting, S., Holzgrefe, H., and Fitzpatrick, F. (1986). Leukotriene B4 and 20-hydroxyleukotriene B4 contract guinea-pig trachea strips in vitro. J. Pharmacol. Exp. Ther. 237, 888-892.

Li, M., Zhang, Z., Koh, H., Lu, R., Jiang, Z., Alioua, A., et al. (2013). The $\beta 1-$ subunit of the MaxiK channel associates with the thromboxane A2 receptor and reduces thromboxane A2 functional effects. J. Biol. Chem. 288, 3668-3677. doi: 10.1074/jbc.M112.426585

Loot, A. E., Moneke, I., Keserü, B., Oelze, M., Syzonenko, T., Daiber, A., et al. (2012). 11,12-EET stimulates the association of BK channel $\alpha$ and $\beta(1)$ subunits in mitochondria to induce pulmonary vasoconstriction. PLoS ONE 7:e46065. doi: 10.1371/journal.pone.0046065

Lu, T., Katakam, P. V., VanRollins, M., Weintraub, N. L., Spector, A. A., and Lee, H. C. (2001). Dihydroxyeicosatrienoic acids are potent activators of $\mathrm{Ca}^{(2+)}$ activated $\mathrm{K}^{(+)}$channels in isolated rat coronary arterial myocytes. J. Physiol. 534, 651-667. doi: 10.1111/j.1469-7793.2001.t01-1-00651.x

Lundbaek, J. A. (2008). Lipid bilayer-mediated regulation of ion channel function by amphiphilic drugs. J. Gen. Physiol. 131, 421-429. doi: 10.1085/jgp.2007 09948

Martín, P., Moncada, M., Enrique, N., Asuaje, A., Valdez Capuccino, J. M., Gonzalez, C., et al. (2013). Arachidonic acid activation of BKCa (Slo1) channels associated to the $\beta 1$-subunit in human vascular smooth muscle cells. Pflugers Arch. doi: 10.1007/s00424-013-1422-x. [Epub ahead of print].

Moczydlowski, E., Alvarez, O., Vergara, C., and Latorre, R. (1985). Effect of phospholipid surface charge on the conductance and gating of a $\mathrm{Ca}^{2+}$ activated $\mathrm{K}^{+}$channel in planar lipid bilayers. J. Membr. Biol. 83, 273-282. doi: 10.1007/BF01868701

Morin, C., Sirois, M., Echave, V., Gomes, M. M., and Rousseau, E. (2007). Relaxing effects of 5-oxo-ETE on human bronchi involve $\mathrm{BK}_{\mathrm{Ca}}$ channel activation. Prostaglandins Other Lipid Mediat. 83, 311-319. doi: 10.1016/j.prostaglandins.2007.03.001

Morin, C., Sirois, M., Echave, V., Rizcallah, E., and Rousseau, E. (2009). Relaxing effects of 17(18)-EpETE on arterial and airway smooth muscles in human lung. Am. J. Physiol. Lung. Cell. Mol. Physiol. 296, L130-L139. doi: 10.1152/ajplung.90436.2008

Orio, P., Rojas, P., Ferreira, G., and Latorre, R. (2002). New disguises for an old channel: MaxiK channel beta-subunits. News Physiol. Sci. 17, 156-161.

Patil, S., Bukiya, A. N., Li, W., Dopico, A. M., and Miller, D. (2008). Design and synthesis of hydroxy-alkynoic acids and their methyl esters as novel activators of BK channels. Bioorg. Med. Chem. Lett. 18, 3427-3430. doi: 10.1016/j.bmcl.2008.03.080

Peters-Golden, M., and Henderson, W. R. Jr. (2007). Leukotrienes. N. Engl. J. Med. 357, 1841-1854. doi: 10.1056/NEJMra071371
Romano, M. R., and Lograno, M. D. (2006). Cannabinoid agonists induce relaxation in the bovine ophthalmic artery: evidences for $\mathrm{CB} 1$ receptors, nitric oxide and potassium channels. Br. J. Pharmacol. 147, 917-925. doi: 10.1038/sj.bjp.0706687

Rosenblum, W. I. (1985). Constricting effect of leukotrienes on cerebral arterioles of mice. Stroke. 16, 262-263. doi: 10.1161/01.STR.16.2.262

Sade, H., Muraki, K., Ohya, S., Hatano, N., and Imaizumi, Y. (2006). Activation of large-conductance, $\mathrm{Ca}^{2+}$-activated $\mathrm{K}^{+}$channels by cannabinoids. Am. J. Physiol. Cell. Physiol. 290, C77-C86. doi: 10.1152/ajpcell. 00482.2004

Shirazi-zand, Z., Ahmad-Molaei, L., Motamedi, F., and Naderi, N. (2013). The role of potassium BK channels in anticonvulsant effect of cannabidiol in pentylenetetrazole and maximal electroshock models of seizure in mice. Epilepsy Behav. 28, 1-7. doi: 10.1016/j.yebeh.2013.03.009

Singh, A. K., McMillan, J., Bukiya, A. N., Burton, B., Parrill, A. L., and Dopico, A. M. (2012). Multiple cholesterol recognition/interaction amino acid consensus (CRAC) motifs in cytosolic $\mathrm{C}$ tail of Slol subunit determine cholesterol sensitivity of $\mathrm{Ca}^{2+}$ - and voltage-gated $\mathrm{K}^{+}$(BK) channels. J. Biol. Chem. 287, 20509-20521. doi: 10.1074/jbc.M112.356261

Stumpff, F., Boxberger, M., Krauss, A., Rosenthal, R., Meissner, S., Choritz, L., et al. (2005). Stimulation of cannabinoid (CB1) and prostanoid (EP2) receptors opens $\mathrm{BK}_{\mathrm{Ca}}$ channels and relaxes ocular trabecular meshwork. Exp. Eye Res. 80, 697-708. doi: 10.1016/j.exer.2004.12.003

Sun, P., Liu, W., Lin, D. H., Yue, P., Kemp, R., Satlin, L. M., et al. (2009). Epoxyeicosatrienoic acid activates BK channels in the cortical collecting duct. J. Am. Soc. Nephrol. 20, 513-523. doi: 10.1681/ASN.2008 040427

Sun, X., Yao, H., Zhou, D., Gu, X., and Haddad, G. G. (2008). Modulation of hSlo BK current inactivation by fatty acid esters of CoA. J. Neurochem. 104, 1394-1403. doi: 10.1111/j.1471-4159.2007.05083.x

Sun, X., Zhou, D., Zhang, P., Moczydlowski, E. G., and Haddad, G. G. (2007). Beta-subunit-dependent modulation of hSlo BK current by arachidonic acid. J. Neurophysiol. 97, 62-69. doi: 10.1152/jn.00700.2006

Tanaka, Y., Yamaki, F., Koike, K., and Toro, L. (2004). New insights into the intracellular mechanisms by which PGI2 analogues elicit vascular relaxation: cyclic AMP-independent, Gs-protein mediated-activation of MaxiK channel. Curr. Med. Chem. Cardiovasc. Hematol. Agents. 2, 257-265. doi: $10.2174 / 1568016043356273$

Tang, Q. Y., Zhang, Z., Meng, X. Y., Cui, M., and Logothetis, D. E. (2014). Structural determinants of PIP2 regulation of BK channel activity through the RCK1 Ca2+ coordination site. J. Biol. Chem. 289, 18860-18872. doi: 10.1074/jbc.M113. 538033

Twitchell, W. A., Peña, T. L., and Rane, S. G. (1997). $\mathrm{Ca}^{2+}$-dependent $\mathrm{K}^{+}$channels in bovine adrenal chromaffin cells are modulated by lipoxygenase metabolites of arachidonic acid. J. Membr. Biol. 158, 69-75.

Vaithianathan, T., Bukiya, A., Liu, J., Liu, P., Asuncion-Chin, M., Fan, Z., et al. (2008). Direct regulation of BK channels by phosphatidylinositol 4,5bisphosphate as a novel signaling pathway. J. Gen. Physiol. 132, 13-28. doi: 10.1085/jgp.200709913

Wang, R. F., Lee, P. Y., Mittag, T. W., Podos, S. M., Serle, J. B., and Becker, B. (1998). Effect of 8-iso prostaglandin E2 on aqueous humor dynamics in monkeys. Arch. Ophthalmol. 116, 1213-1216. doi: 10.1001/archopht.116. 9.1213

White, R., Ho, W. S., Bottrill, F. E., Ford, W. R., and Hiley, C. R. (2001). Mechanisms of anandamide-induced vasorelaxation in rat isolated coronary arteries. $\mathrm{Br} . J$. Pharmacol. 134, 921-929. doi: 10.1038/sj.bjp.0704333

Wu, S. N., Li, H. F., and Chiang, H. T. (2000). Actions of epoxyeicosatrienoic acid on large-conductance $\mathrm{Ca}^{(2+)}$-activated $\mathrm{K}^{(+)}$channels in pituitary GH(3) cells. Biochem. Pharmacol. 60, 251-262. doi: 10.1016/S0006-2952(00) 00317-8

Xu, H., Qi, J., Wang, G., Deng, H., and Qi, Z. (2011). The effect of single cerebroside compounds on activation of $\mathrm{BK}_{\mathrm{Ca}}$ channels. Mol. Membr. Biol. 28, 145-154. doi: $10.3109 / 09687688.2010 .538731$

Yeagle, P. L. (2014). Non-covalent binding of membrane lipids to membrane proteins. Biochim. Biophys. Acta. 1838, 1548-1559. doi: 10.1016/j.bbamem.2013.11.009

Yuan, C., O'Connell, R. J., Jacob, R. F., Mason, R. P., and Treistman, S. N. (2007). Regulation of the gating of $\mathrm{BK}_{\mathrm{Ca}}$ channel by lipid bilayer thickness. J. Biol. Chem. 282, 7276-7286. doi: 10.1074/jbc.M607593200 
Zhang, Y., Oltman, C. L., Lu, T., Lee, H. C., Dellsperger, K. C., and VanRollins, M. (2001). EET homologs potently dilate coronary microvessels and activate $\mathrm{BK}_{(\mathrm{Ca})}$ channels. Am. J. Physiol. Heart. Circ. Physiol. 280, $\mathrm{H} 2430-\mathrm{H} 2440$.

Zhu, S., Han, G., and White, R. E. (2002). PGE2 action in human coronary artery smooth muscle: role of potassium channels and signaling cross-talk. J. Vasc. Res. 39, 477-488. doi: 10.1159/000067201

Conflict of Interest Statement: The authors declare that the research was conducted in the absence of any commercial or financial relationships that could be construed as a potential conflict of interest.
Received: 29 May 2014; accepted: 31 July 2014; published online: 22 August 2014. Citation: Dopico AM and Bukiya AN (2014) Lipid regulation of BK channel function. Front. Physiol. 5:312. doi: 10.3389/fphys.2014.00312

This article was submitted to Membrane Physiology and Membrane Biophysics, a section of the journal Frontiers in Physiology.

Copyright (๑) 2014 Dopico and Bukiya. This is an open-access article distributed under the terms of the Creative Commons Attribution License (CC BY). The use, distribution or reproduction in other forums is permitted, provided the original author $(s)$ or licensor are credited and that the original publication in this journal is cited, in accordance with accepted academic practice. No use, distribution or reproduction is permitted which does not comply with these terms. 